Journal for ImmunoTherapy of Cancer

\title{
$C$ reactive protein impairs adaptive immunity in immune cells of patients with melanoma
}

\author{
Tatsuya Yoshida (D) , ${ }^{1}$ Junya Ichikawa, ${ }^{1}$ Iulia Giuroiu, ${ }^{1}$ Andressa S Laino, ${ }^{1}$ \\ Yuhan Hao, ${ }^{2}$ Michelle Krogsgaard, ${ }^{1}$ Melinda Vassallo, ${ }^{1}$ David M Woods, ${ }^{1}$ \\ F Stephen Hodi, ${ }^{3}$ Jeffrey Weber ${ }^{1}$
}

To cite: Yoshida T, Ichikawa J, Giuroiu I, et al. C reactive protein impairs adaptive immunity in immune cells of patients with melanoma. Journal for ImmunoTherapy of Cancer 2020;8:e000234. doi:10.1136/ jitc-2019-000234

- Additional material is published online only. To view, please visit the journal online (http://dx.doi.org/10.1136/jitc2019-000234).

$T Y$ and $\mathrm{Jl}$ contributed equally.

Accepted 24 February 2020

Check for updates

(c) Author(s) (or their employer(s)) 2020. Re-use permitted under CC BY-NC. No commercial re-use. See rights and permissions. Published by BMJ.

1 Laura and Isaac Perlmutter Cancer Center, NYU Langone Health, New York, NY, USA ${ }^{2}$ Center for Genomics and Systems Biology, Department of Biology, New York University, New York, NY, USA

${ }^{3}$ Dana-Farber Cancer Institute, Boston, MA, USA

Correspondence to

Dr Jeffrey Weber;

Jeffrey.Weber@nyulangone.org

\section{ABSTRACT}

Background High $\mathrm{C}$ reactive protein (CRP) levels have been reported to be associated with a poor clinical outcome in a number of malignancies and with programmed cell death protein 1 immune checkpoint blockade in patients with advanced cancer. Little is known about the direct effects of CRP on adaptive immunity in cancer. Therefore, we investigated how CRP impacted the function of T cells and dendritic cells (DCs) from patients with melanoma.

Methods The effects of CRP on proliferation, function, gene expression and phenotype of patient $T$ cells and DCs, and expansion of MART-1 antigen-specific T cells were analyzed by multicolor flow cytometry and RNA-seq. Additionally, serum CRP levels at baseline from patients with metastatic melanoma treated on the Checkmate-064 clinical trial were assessed by a Luminex assay.

Results In vitro, CRP inhibited proliferation, activationassociated phenotypes and the effector function of activated CD4+ and CD8+ Tcells from patients with melanoma. CRPtreated $T$ cells expressed high levels of interleukin-1 $\beta$, which is known to enhance CRP production from the liver. CRP also suppressed formation of the immune synapse and inhibited early events in T-cell receptor engagement. In addition, CRP downregulated the expression of costimulatory molecules on mature DCs and suppressed expansion of MART-1-specific CD8+ T cells in a dose-dependent manner by impacting on both $T$ cells and antigen-presenting cells. High-serum CRP levels at baseline were significantly associated with a shorter survival in both nivolumab-treated and ipilimumab-treated patients.

Conclusions These findings suggest that high levels of CRP induce an immunosuppressive milieu in melanoma and support the blockade of CRP as a therapeutic strategy to enhance immune checkpoint therapies in cancer. Trial registration number NCT01783938 and NCT02983006.

\section{BACKGROUND}

$\mathrm{C}$ reactive protein (CRP) is a pentameric protein (pentraxin) synthesized by the liver, and also to a lesser degree by smooth muscle cells, macrophages, endothelial cells, lymphocytes and adipocytes in response to interleukin (IL)-6 and IL-1 $\beta .^{12}$
CRP levels in the serum are highly elevated in response to acute inflammation and, to a lesser degree, chronic inflammation. CRP binds to lysophosphatidylcholine on the surface of dead or dying eukaryotic cells and bacteria, activating complement via C1q. ${ }^{1}$ It was first identified in the serum of patients with infection as a molecule that reacted with the somatic ' $\mathrm{C}$ ' carbohydrate antigen of pneumococcus. ${ }^{1}$ Normal levels in healthy individuals reach up to $5-10 \mu \mathrm{g} / \mathrm{mL}$, but patients with cancer can display CRP levels $>500 \mu \mathrm{g} / \mathrm{mL}$.

A number of studies have shown that high CRP levels are associated with increased cancer risk, but the mechanisms by which that occurs are unclear and little is known about the effects of elevated CRP on immune function in patients with cancer. Recent data suggest that chronic inflammation and high CRP levels are associated with poor survival in renal cell, lung, pancreatic and breast cancer, in patients with head and neck cancer treated with radiotherapy and that CRP is associated with bone destruction in multiple myeloma. ${ }^{3-9}$ CRP has been shown to supress $\mathrm{T}$ cell function in autoimmunity in mouse models and to suppress dendritic cell function in normals. ${ }^{10}{ }^{11}$ High CRP levels have been shown in small studies to be associated with a poor outcome with the use of the cytotoxic T-lymphocyte-associated protein 4 (CTLA-4) blocking antibody tremelimumab. ${ }^{12}$ A recent study demonstrated a significant association between pretreatment CRP levels and progression-free and overall survival in patients with lung cancer treated with programmed cell death protein 1 (PD-1) immune checkpoint blockade. ${ }^{13}$ These data are consistent with our published data, which demonstrated that acute phase proteins including CRP, serum amyloid A and $\mathrm{P}$ and complement components were associated with a poor clinical outcome in patients with melanoma treated with PD-1 blockade. ${ }^{14}$ 
In spite of decades of monitoring CRP and other chronic inflammatory mediators in patients with cancer, little is known about the direct effects of CRP on adaptive immunity in cancer. In the current work, we explored how CRP impacted on the phenotype and function of effector $\mathrm{T}$ cells and dendritic cells (DCs) derived from patients with melanoma, and generated a hypothesis as to the mechanism by which CRP suppressed adaptive immunity. Using patient samples and in vitro assays, we demonstrated that CRP negatively impacted DC and T-cell function, supporting a hereto unknown role for CRP and acute phase proteins in immunosuppression. These results highlight the clinical potential of targeting CRP and acute phase proteins (eg, by IL-1 $\beta$ and/or IL-6 inhibitors) as means to overcome resistance to immune checkpoint blockade.

\section{METHODS \\ Patient samples}

Peripheral blood samples and serum were obtained from patients with metastatic melanoma under an Institutional Review Board-approved protocol. ${ }^{15}$ Samples were coded with an anonymized 5-digit number and their identity was unknown to those performing the experiments. Peripheral blood mononuclear cells (PBMCs) were isolated by density gradient with $1.077 \mathrm{~g} / \mathrm{mL}$ Ficoll-Paque (GE Healthcare, Chicago, Illinois, USA). For cryopreservation, $\mathrm{PBMCs}$ were re-suspended in human $\mathrm{AB}$ serum (Omega Scientific; Tarzana, California, USA) with $10 \%$ dimethyl sulfoxide (Sigma-Aldrich, St Louis, Missouri, USA), frozen at $-80^{\circ} \mathrm{C}$ and stored in liquid nitrogen. CD3+ and CD8+ Tcells were isolated using a magnetic negative selection kit (StemCell Technologies, Vancouver, British Columbia, Canada). Cells were cultured with $10 \%$ $\mathrm{AB}$ human serum in beta-mercaptoethanol, non-essential amino acids, HEPES, penicillin, streptomycin and gentamicin supplemented X-VIVO media (Corning, Corning, New York, USA). Serum was obtained from whole blood patient samples, centrifuged to remove cells and frozen at $-80^{\circ} \mathrm{C}$ until time of use.

\section{Analysis for serum CRP levels in patients with melanoma}

A total of 95 patients with melanoma from the Checkmate-064 trial ${ }^{15}$ had available serum for CRP testing by a magnetic bead-based assay (R\&D Systems, Minneapolis, Minnesota, USA), performed according to the manufacturer (29 samples from cohort A, 66 from cohort B). A Luminex MagPix instrument (R\&D) was used for sample acquisition.

\section{Reagents}

Recombinant human IL-2 (Aldesleukin, Prometheus Laboratories, San Diego, California, USA), C3a, C5a, IL-4, IL-7, IL-15, IL-21 and granulocyte-macrophage colony-stimulating factor (GM-CSF) (R\&D) and sodium azide-free, endotoxin-free CRP (R\&D, and US Biological; Salem, Massachusetts, USA) were commercially obtained.
aCD3 (clone OKT3), $\alpha \mathrm{CD} 28$ (clone CD28.2) and IgG4 antibodies were obtained from Biolegend (San Diego, California, USA).

\section{Flow cytometry analysis}

Cells were washed using phosphate-buffered saline with $2 \%$ fetal calf serum, and stained with monoclonal antibodies (mAbs) specific for CD3 (UCHT1, BD Biosciences, Franklin Lakes, New Jersey, USA), CD4 (RPA-T4, BD Biosciences), CD8 (RPA-T8, BD Biosciences), CD45RA (HI100, BD Biosciences), CD62L (DREG-56, eBioscience, San Diego, California, USA), CD40 (5C3, BD Biosciences), CD80 (L307.4, BD Biosciences), CD83 (HB15e, BD Biosciences), CD86 (2331, BD Biosciences), PD-1 (MIH4, BD Biosciences), PD-L1 (.MIH1, BD Biosciences), ICOS (DX29, BD Biosciences), CD223 (LAG-3) (3DS223H, eBioscience), Tim-3 (F38-2E2, BD Biosciences), CD137 (4-1BB) (4B4-1, BioLegend), CD69 (FN50, BD Biosciences), CD134 (OX-40) (ACT35, BD Biosciences) or CD152 (CTLA-4) (BNI3, BD Biosciences). Intracellular staining of Ki67 (B56, BD Biosciences), EOMES (WD1928, eBioscience), T-BET (O4-46, BD Biosciences), GRANZYME A (CB9, eBioscience), GRANZYME B (GB11, BD Biosciences), GRANZYME K (G3H69, eBioscience), PERFORIN (b-D48, BioLegend) and CRP (Abcam, Cambridge, Massachusetts, USA) were performed after fixation and permeabilization using Foxp3 kit (eBioscience), according to manufacturer's instructions. Live Dead dyes (Invitrogen, Carlsbad, California, USA) were used to assess viable cells. The cells in all experiments were analyzed with an Attune NXT flow cytometer (ThermoFisher Scientific, Waltham, Massachusetts, USA) and data were analyzed using FlowJo 10 software (FlowJo, Ashland, Oregon, USA).

\section{Stimulation of CD3+ or antigen-specific CD8+ $T$ cells}

CD3+ or CD8+ T cells were labeled with $2.5 \mu \mathrm{M}$ carboxyfluorescein succinimidyl ester (CFSE) or CellTrace Violet (Invitrogen) for $5 \mathrm{~min}$ at $37^{\circ} \mathrm{C}$. Cells were stimulated with $\gamma$-irradiated PBMCs pulsed with MART-1 peptide, or anti-CD3/CD28 mAb (Dynabeads, ThermoFisher) for $72-120$ hours. To investigate CRP uptake, cells were treated with mitomycin C (Sigma).

\section{Intracellular cytokine staining}

CD3+ Tcells were treated for 72 hours with CRP at the indicated concentrations, in the presence of IL-2 $(100 \mathrm{IU} / \mathrm{mL})$, then stimulated for 4 hours with phorbol 12-myristate 13-acetate (PMA) and ionomycin (plus protein transport inhibitors) (Invitrogen). Cells were stained for cell surface markers followed by intracellular cytokines (interferon (IFN)- $\gamma$ (4S.B3, BD Biosciences), tumor necrosis factor (TNF)- $\alpha$ (MAb11, BD Biosciences) and IL-2 (MQ1-17H12, BD Biosciences)) after fixation and permeabilization.

\section{T-cell receptor signaling analysis by flow cytometry}

CD3+ Tcells were treated with CRP at the indicated concentrations, washed once with medium and stimulated 
with $\mathrm{H}_{2} \mathrm{O}_{2}$ for $30 \mathrm{~min}$. Cells were stained by flow cytometry for cell surface and phosphoprotein makers (ZAP70 (pY319)/Syk (pY352) (17A/P-ZAP70, BD Biosciences), LCK (pY505) (4/LCK-Y505, BD Biosciences) and LAT (pY717) (I58-1169, BD Biosciences) (M89-61, BD Biosciences)) after fixation and permeabilization using a transcription factor phosphor-buffer set (BD Biosciences).

\section{Calcium influx analysis}

CD3+ Tcells were treated with CRP at the indicated concentrations, stained by flow cytometry for surface markers, then loaded with $\mathrm{Ca}^{2+}$ indicator using a calcium assay kit (BD Biosciences) for 1 hour at $37^{\circ} \mathrm{C}$ after staining for cell surface makers. Intracellular $\mathrm{Ca}^{2+}$ influx after PMA and ionomycin (Invitrogen) was monitored for $5 \mathrm{~min}$ by flow cytometry.

\section{Generation of monocyte-derived dendritic cells}

CD14+ cells were purified from PBMCs using a human CD14-positive selection kit (StemCell), cultured with $20 \mathrm{ng} / \mathrm{mL}$ GM-CSF and $20 \mathrm{ng} / \mathrm{mL}$ IL-4 with replacement with fresh medium containing the cytokines 3 days later, and harvested on day 6 to generate immature DCs (iDCs) for subsequent experiments. ${ }^{16}$ To generate mature DCs (mDCs), $1 \mu \mathrm{g} / \mathrm{mL}$ lipopolysaccharide (LPS) (SigmaAldrich) was added to iDCs cultures for 48 hours.

\section{Generation of antigen-specific CD8+ T cells}

Antigen-presenting cells (APCs) (PBMCs or mature DCs) were pulsed with $10 \mu \mathrm{M}$ Melan-A26-35 (EAAGIGILTV) peptides (BioSynthesis, Lewisville, Texas, USA) specific for HLA-A*0201 for 2 hours. After $35 \mathrm{~Gy}$-irradiation (CellRad, Faxitron, Tucson, Arizona, USA), APCs were cultured in round-bottom 96-well plates containing sorted CD8+ Tcells previously cultured for 7 days. ${ }^{16} 17$ Half of the medium was replaced with fresh medium containing $20 \mathrm{IU} / \mathrm{mL}$ IL-2, $10 \mathrm{ng} / \mathrm{mL}$ IL-7, $10 \mathrm{ng} / \mathrm{mL}$ IL-15 and $20 \mathrm{ng} / \mathrm{mL}$ IL-21 on the next day. MART-1-specific CD8+ T cells were detected by direct flow staining with MART-1/ HLA-A*0201 tetramer PE (MBL, Woburn, Massachusetts, USA).

\section{RNA-seq analysis}

CD8+ Tcells were cultured with CRP or no additional treatment at the indicated concentrations and with APC previously pulsed with MART-1 peptides, as described below for 5 days. Total RNA was isolated with the RNeasy Mini Kit (Qiagen, Venlo, The Netherlands). RNA quality and quantity were analyzed on a Bioanalyzer 2100 (Agilent, Santa Clara, California, USA) using a pico chip. Indexed cDNA libraries were pooled and sequenced on a HiSeq2500 machine (Illumina, San Diego, California, USA). Sequencing results were demultiplexed and converted to FASTQ format by using bcl2fastq software. All paired RNA reads were mapped to the human reference genomes hg38 using the aligner STAR. ${ }^{18}$ Then, we applied featureCounts to the BAM files from STAR and generated counts for each gene based on the number of aligned reads which overlapped its exons. ${ }^{19}$ The normalization of RNA expression counts and differential analysis were performed by the DESeq 2 by using negative binomial generalized linear models. ${ }^{20}$

\section{Analysis of CRP cellular localization}

CD3+ T cells in the presence or absence of CRP for 1 hour were settled onto poly-lysine-coated slides, stained with 4',6-diamidino-2-phenylindole (DAPI) (Invitrogen) after fixation and permeabilization using Image-iT Fixation/ Permeabilization Kit (Invitrogen), and then stained with fluorescein isothiocyanate (FITC)-conjugated CRP antibody (Abcam) and Alexa Fluor 594-conjugated antihuman CD4, and CD8a analyzed by confocal microscopy (LSM 880, Zeiss, Jena, Germany).

\section{Immunological synapse detection}

To detect the immunological synapse, CD3+ Tcells were treated for 48 hours with CRP at the indicated concentrations, then activated with anti-CD3/CD28 mAb (Dynabeads) for 10-30 min. Co-cultures of cells and beads were settled onto poly-lysine-coated slides, fixed in $4 \%$ formaldehyde and stained with DAPI, FITC-conjugated CRP antibody and Texas Red-X Phalloidin (Invitrogen) then analyzed by confocal microscopy (Zeiss LSM 880), as previously described. ${ }^{21} 22$

\section{Statistical analysis}

Differences between two groups (control and treatment groups) were analyzed by Student's two-tailed paired t-test using Prism V.8 software (GraphPad, San Diego, California, USA). The survival probabilities were estimated using the Kaplan-Meier method, where differences in the variables were calculated using the log-rank test. $P$ values $<0.05$ were considered to be statistically significant.

\section{RESULTS}

\section{CRP binds $\mathrm{T}$ cells and inhibits proliferation}

To investigate the influence of CRP on adaptive T-cell immunity, we first examined the impact of CRP on proliferation of CD3/CD28-activated CD8+ and CD4+ Tcells. As shown in figure 1A, CD8+ Tcells treated with CRP had significantly decreased percentages of cells with $\geq 3$ divisions $(\mathrm{p}<0.05)$, as determined by Cell Trace Violet Staining. After 72 hours of treatment, approximately $40 \%$ of CD8+ Tcells were positive for CRP, with a plateau at $40 \mu \mathrm{g} / \mathrm{mL}$ (figure $1 \mathrm{~B}, \mathrm{p}<0.01$ ). Similar data were seen for CD4+ T cells with up to $25 \%$ positivity (online supplementary figure $1 \mathrm{~A}$ ). $\mathrm{T}$ cells are not known to express CRP, ${ }^{1}$ and the non-treated control CD8+ and CD4+ groups demonstrated no positivity for CRP, supporting that the observed positivity was from uptake of exogenous CRP. CRP staining was inhibited by mitomycin $\mathrm{C}$ as shown in figure 1B, suggesting that it was dependent on cell division. Uptake was seen as early as 15 min after exposure (data not shown). CRP exposure for 72 hours also consistently inhibited Ki67 expression in activated CD8+ and CD4+ T cells (online supplementary figure 2A/B). 
A.

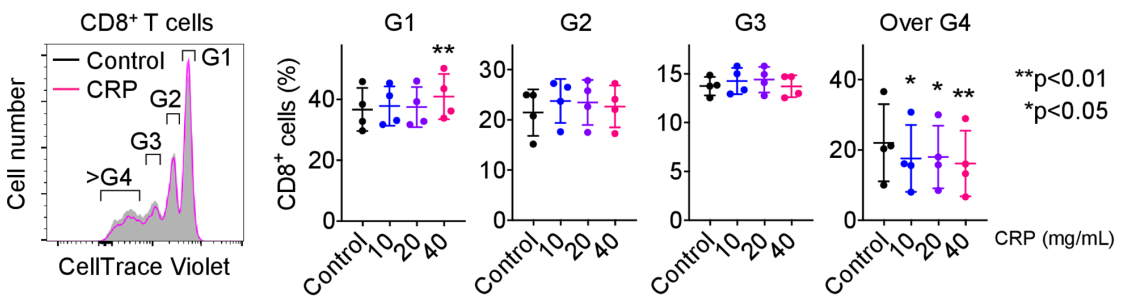

CRP $(40 \mathrm{mg} / \mathrm{mL})$

B.
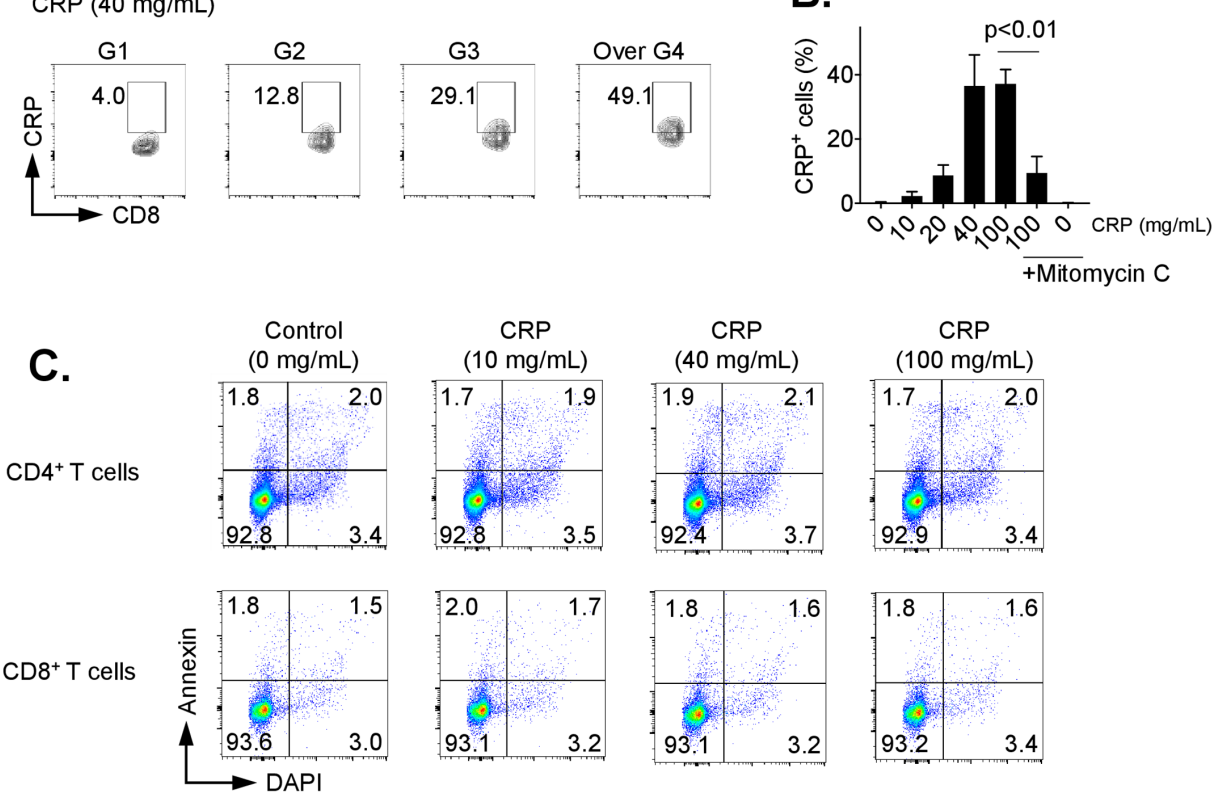

D.

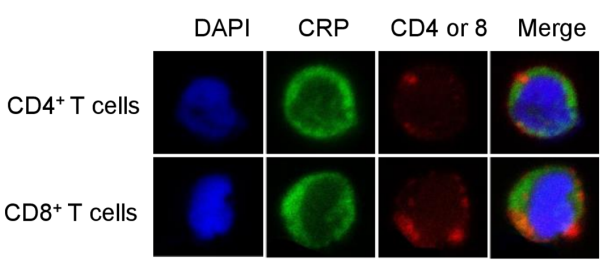

E.

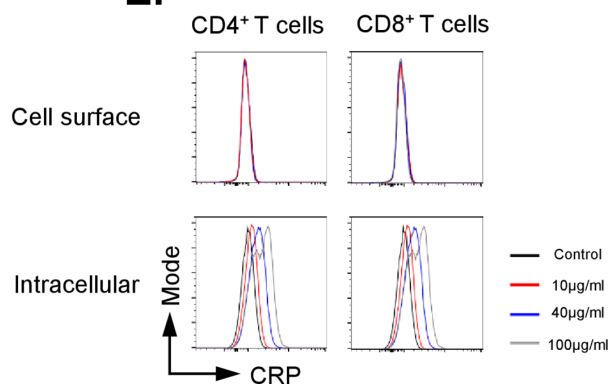

Figure $1 \mathrm{C}$ reactive protein (CRP) affects the proliferation on activated T cells. CD3+ Tcells were isolated by negative magnetic separation from baseline patient peripheral blood mononuclear cells (PBMC), and activated with CD3/CD28 antibody for 72 hours in the presence of different CRP concentration. (A) Proliferation analysis of CellTrace Violet-labeled CD3+ T cells stimulated with anti-CD3 and CD28 monoclonal antibodies (mAbs) for 72 hours. The cell ratio and CRP+ population of CD8+ cells in each generation (G1 to over G4) were detected. ${ }^{*} \mathrm{P}<0.05$, ${ }^{* *} \mathrm{p}<0.01$ relative to control. (B) Representative data of CRP uptake by CD3+/CD8+ T cells. The uptake of CRP was dose-dependent and inhibited by mitomycin C. Error bars are SD for triplicate samples assessed. (C) Annexin V (BD Biosciences) and 4',6-diamidino-2-phenylindole (DAPI) double staining of CD3+ Tcells treated with CRP at doses of 10,40 or $100 \mu \mathrm{g} / \mathrm{mL}$ for 24 hours. (D) CD3+ T cells pretreated with CRP at $100 \mu \mathrm{g} / \mathrm{mL}$ were stained with anti-CD4, CD8 (red) and CRP (green) antibodies, and nuclei were stained with DAPI. Stained cells were analyzed under a confocal microscope. (E) The frequency of CRP-treated CD4 and CD8 T cells stained with anti-CRP antibody before permeabilization (cell surface) was compared with cells after permeabilization (intracellular) by flow cytometry.

CRP is also known to activate the classical complement pathway. ${ }^{12}$ No impact on T-cell proliferation was observed with treatment using C3a and C5a, which are major cleavage components of the classical complement pathway (online supplementary figure 2C). In addition, we analyzed whether LPS affects T-cell proliferation, since the commercial CRP might be contaminated with trace LPS; no impact on proliferation was observed after treatment with LPS (online supplementary figure 2D). 
To determine the impact of CRP on T-cell viability, CD3+ cells were treated for 24 hours with CRP at doses ranging from 10 to $100 \mu \mathrm{g} / \mathrm{mL}$. T-cell apoptosis was evaluated by staining with annexin $V$ and DAPI on cells from at least three patients. There was no significant difference in the percentage of annexin V+/DAPI- $(6.23 \%$ vs $6.28 \%)$ nor annexin V+/DAPI+ (1.52\% vs $1.67 \%$ ) (figure 1C). T-cell treatment with CRP for 24 hours also had no significant effect on active caspase 3, 8 and 9 expression (online supplementary figure $3 \mathrm{~A}$ ).

We also evaluated the effect of CRP on cell cycle progression. After 72 hours of activation by PMA and ionomycin, CRP induced G0/G1 cell cycle arrest in CD3+ $\mathrm{T}$ cells (online supplementary figure $3 \mathrm{~B}$ ). These results suggest that CRP inhibited T-cell proliferation but had no impact on apoptosis or cell death.

\section{CRP is internalized by $\mathrm{T}$ cells after treatment}

We next examined the localization of CRP in T cells after CRP $(10-100 \mu \mathrm{g} / \mathrm{mL})$ treatment using confocal microscopy. CRP was internalized by $\mathrm{T}$ cells 24 hours after CRP exposure in vitro, as shown in figure 1D. Following CRP treatment $(10-100 \mu \mathrm{g} / \mathrm{mL})$ for 1 hour, we assessed surface versus intracellular CRP presence in T cells by flow cytometry. T cells stained with anti-CRP antibody before permeabilization did not display CRP bound on the surface of CD4+ and CD8+ cells, but 20\%-40\% of T cells stained with anti-CRP antibody after permeabilization were positive for CRP (figure 1E). The presence of CRP in T cells increased in a dose-related manner 24 hours after CRP treatment (online supplementary figure 3C), suggesting that CRP is internalized after exposure.

\section{FcR blockade does not reverse CRP internalization and inhibition of proliferation in CRP-treated T cells}

While CRP binds to eukaryotic and microbial phosphocholine, ${ }^{12}$ playing a role in innate immunity, viable T cells do not express membrane phosphocholine. IgG Fc receptors (FcR: CD16, CD32 and CD64) have also been identified as receptors for CRP on a variety of cells. However, little evidence supports the expression of FcRs by T cells. ${ }^{23}$ Fewer than $10 \%$ of CD4+ and CD8+ T cells express CD16, CD32 or CD64 (online supplementary figure 4A). To determine if blocking FCR hindered CRP internalization and inhibition of T-cell proliferation, sorted CD3+ T cells were cultured with CRP at concentrations ranging from 10 to $100 \mu \mathrm{g} / \mathrm{mL}$ in the presence of anti-CD16, anti-CD32 or anti-CD64 antibodies. These blocking antibodies did not reverse the binding of CRP to CD4/8T cells (online supplementary figure 4B) nor did they alter the effects of CRP on the proliferation of $\mathrm{T}$ cells (online supplementary figure $4 \mathrm{C}$ ).

\section{CRP alters phenotype, activation and checkpoint protein expression of activated $\mathrm{T}$ cells}

To determine whether CRP alters T-cell phenotypes, we treated CD3/CD28-stimulated, flow-sorted CD3+ Tcells of patients with melanoma with CRP at doses from 10 to $40 \mu \mathrm{g} / \mathrm{mL}$, for 72 hours. CD4+ and CD $8+$ $\mathrm{T}$ cells were categorized based on CD62L (L-selectin) and CD45RA expression into naïve CD45RA+CD62L+ (TN), CD45RA+CD62L+CDF95+ $\left(\mathrm{T}_{\mathrm{SCM}}\right)$, central memory CD45RA-CD62L+ $\left(\mathrm{T}_{\mathrm{CM}}\right)$, effector memory CD45RACD62L- $\left(\mathrm{T}_{\mathrm{EM}}\right)$ and effector CD45RA+CD62L- $\left(\mathrm{T}_{\mathrm{E}}\right)$ populations. CRP treatment did not result in any significant differences in the frequency of CD8+ (online supplementary figure $5 \mathrm{~A}$ ) or $\mathrm{CD} 4+$ (online supplementary figure $6 \mathrm{~A}$ ) T-cell phenotypes relative to controls. In contrast, CRPexpressing cells exhibited a small and non-significant decrease in the frequency of $\mathrm{T}_{\mathrm{N}} \mathrm{CD} 8+$ cells $(3.4 \%-1.6 \%)$, $\mathrm{T}_{\mathrm{E}}$ CD8+ cells $(7 \%-4 \%)$ and increase in $\mathrm{T}_{\mathrm{CM}}$ and $\mathrm{T}_{\mathrm{SCM}}$ CD8+ cells $(32.3 \%-36.9 \%$ and $13.1 \%-16.3 \%$ ) (online supplementary figure $5 \mathrm{~B}$ ). Similar results were observed for CD4+ T cells (online supplementary figure 6B).

Since inhibitory checkpoint receptors (eg, CTLA-4, PD-1) and activating molecules (eg, ICOS, 4-1BB) are upregulated during T-cell activation, we evaluated expression of these proteins on $\mathrm{T}$ cells after CRP treatment. Heatmaps show that CRP at doses up to $40 \mu \mathrm{g} / \mathrm{mL}$ significantly increased protein expression of 4-1BB, CTLA-4, ICOS, LAG3 and TBET in CRP+ CD8+ T cells (figure 2A, $\mathrm{p}<0.05)$ and 4-1BB, ICOS, EOMES, PD-1, TBET, TIM3 and PERFORIN in CRP+ CD4+ T cells (figure 2B, $\mathrm{p}<0.05$ ), compared with their counterpart CRP- T cells.

We next investigated the effects of CRP on IFN- $\gamma$, TNF- $\alpha$ and IL-2 cytokine production. CD3+ T cells were cultured for 72 hours with CRP at doses from 10 to $100 \mu \mathrm{g} / \mathrm{mL}$, and subsequently stimulated for 4 hours with PMA/ ionomycin. Addition of CRP $(100 \mu \mathrm{g} / \mathrm{mL})$ inhibited intracellular cytokine expression, with a reduction by $13 \%(\mathrm{p}=0.0005)$ and $30 \%(\mathrm{p}=0.0003)$ in IL-2 and IFN- $\gamma$ by $\mathrm{CD} 4+\mathrm{T}$ cells, and by $6.5 \%(\mathrm{p}=0.0285)$ and $25.5 \%$ $(\mathrm{p}=0.0005)$ in CD8+ T cells (figure 2C). In contrast, CRP increased TNF- $\alpha$ production by $10 \%(\mathrm{p}=0.0002)$ and 9.6\% ( $\mathrm{p}=0.0008$ ) in CD4+ and CD8+ Tcells (figure 2C). We also analyzed intracellular granzyme B expression, as a surrogate of cytolytic activity, after CRP treatment of $\mathrm{T}$ cells activated via CD3/CD28 for 72 hours. No impact on CD4+ and CD8+ granzyme $\mathrm{B}$ expression was observed with $\mathrm{CRP}$ treatment up to $100 \mu \mathrm{g} / \mathrm{mL}$ (figure $2 \mathrm{C}$ ).

\section{CRP inhibits TCR signaling in T cells}

To determine the effects of CRP on T-cell receptor (TCR) signaling, we employed flow cytometry to measure phosphorylated TCR signaling intermediates expressed by CD3+ T cells pretreated with CRP and concomitantly stimulated with $\mathrm{H}_{2} \mathrm{O}_{2}$. Exogenously added $\mathrm{H}_{2} \mathrm{O}_{2}$ induces phosphorylation of functionally relevant TcR tyrosine residues in a manner similar to TCR engagement by antiCD3 antibodies, resulting in potent phosphorylation of TCR signal pathway intermediates such as LCK, ZAP70 and LAT. ${ }^{24}{ }^{25}$ CRP treatment at doses of 10 to $100 \mu \mathrm{g} /$ $\mathrm{mL}$ for 72 hours blocked $\mathrm{H}_{2} \mathrm{O}_{2}$-triggered phosphorylation of LCK (early), ZAP70 (intermediate), LAT (late) and ERK (late) on both CD4+ and CD8+ T cells in a dosedependent manner (figure $3 \mathrm{~A}$ ). 
A.

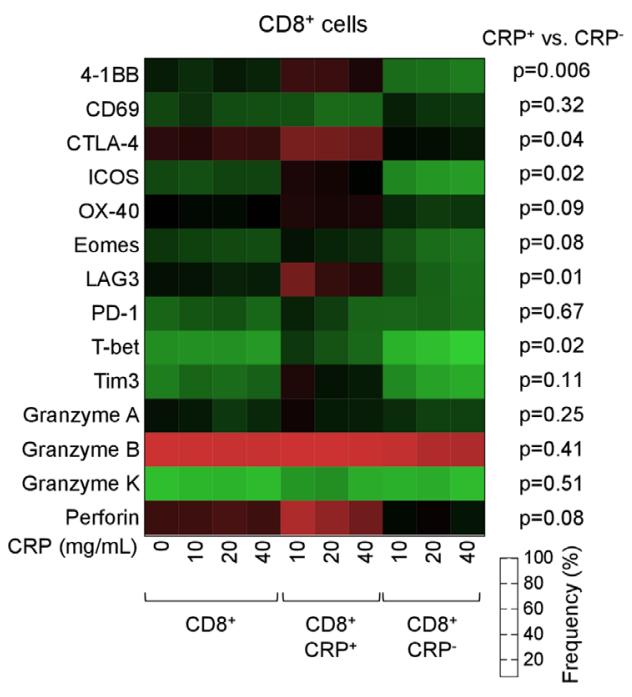

B.

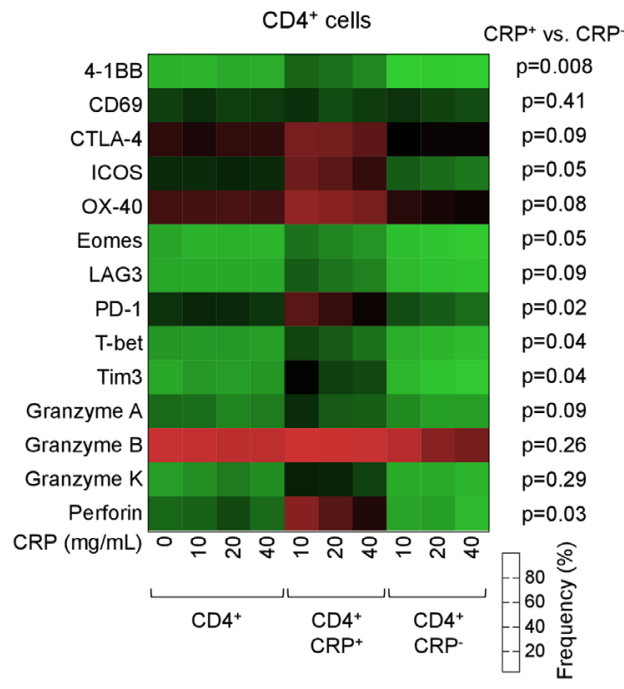

C.

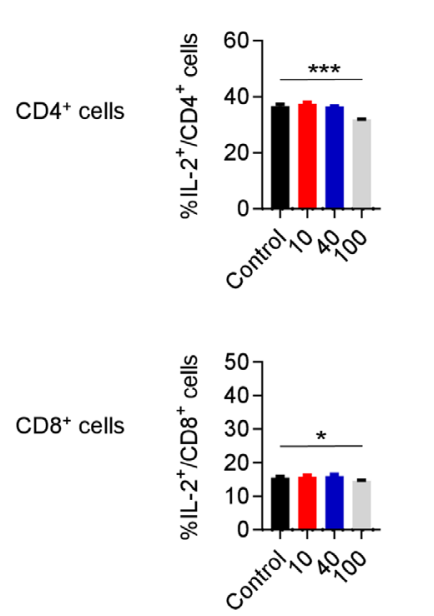

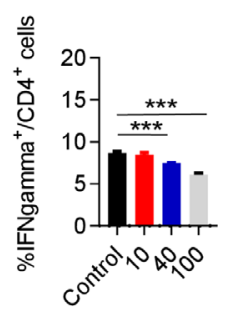
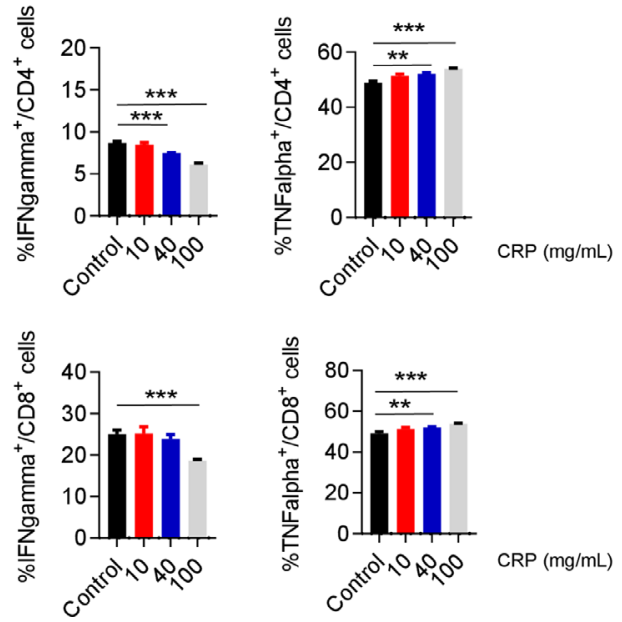

Figure 2 C reactive protein (CRP) affects the function of activated T cells. Expression of checkpoint, stimulatory and cytolytic proteins by flow cytometry on activated CD8 (A) and CD4 (B) T cells treated with CRP at 10, 20 and $40 \mu \mathrm{g} / \mathrm{mL}$ as a heat map. Representative data from three patients. (C) CD3+ T cells isolated from baseline peripheral blood mononuclear cells (PBMC) samples of patients with melanoma prior to any treatment were cultured for 72 hours with or without CRP at doses of 10,40 and $100 \mu \mathrm{g} / \mathrm{mL}$, and subsequently stimulated for 4 hours with phorbol 12-myristate 13-acetate (PMA)/ionomycin for analysis of intracellular cytokine production (interferon (IFN)- $\gamma$, tumor necrosis factor (TNF)- $\alpha$ and interleukin (IL)-2) and granzyme B. Representative data from five patients. Error bars are +SEM for triplicate samples assessed. ${ }^{\star \star} P<0.05,{ }^{\star \star} p<0.01,{ }^{* \star \star} p<0.001$ relative to cells with no treatment.

We next determined whether CRP affected calcium influx in T cells, one of the key early signaling events on binding of TCR by antigen-major histocompatibility complex (MHC), playing an important role in T-cell activation, proliferation and differentiation. CD3+ T cells treated with CRP for 72 hours at $10-100 \mu \mathrm{g} / \mathrm{mL}$ were activated with PMA and ionomycin. CRP suppressed calcium influx by both CD4+ and CD8+ T cells in a dose-dependent manner (figure 3B).

To confirm that binding of CRP to $\mathrm{T}$ cells affected early events in TCR signaling, we determined whether CRP blocked formation of the immunological synapse by measuring actin focused at the interface between CD3/ CD28 stimulatory beads and T cells. CD3+ Tcells treated with $100 \mu \mathrm{g} / \mathrm{mL}$ CRP activated with CD3/CD28 beads were stained for actin, DAPI and CRP (figure 3C-D). T cells that up took CRP formed significant fewer immunological synapses at the bead/T-cell interface, as denoted by actin staining, compared with those without CRP intake ( $46.0 \%$ vs $29.4 \%, \mathrm{p}=0.0481$ ). These data suggest that CRP blocked formation of immunological synapses, inhibiting the earliest events in TCR signaling, and are consistent with CRP-induced decrease in phosphorylation of LCK, ZAP70 and LAT, which are required for lipid raft formation.

\section{CRP inhibits activation and expression of costimulatory molecules on mature dendritic cells}

To investigate whether CRP influences antigen presentation, we assessed expression of the DC maturation marker 
A.

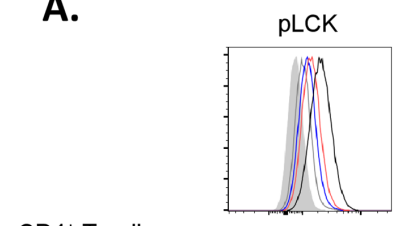

$\mathrm{CD}^{+} \mathrm{T}$-cells
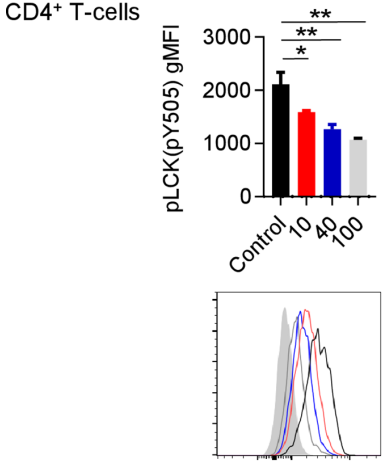

$\mathrm{CD}^{+} \mathrm{T}$-cells

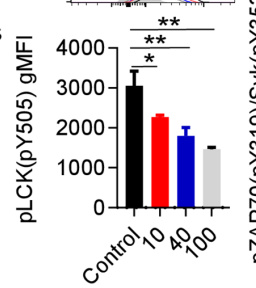

pZAP70/Syk

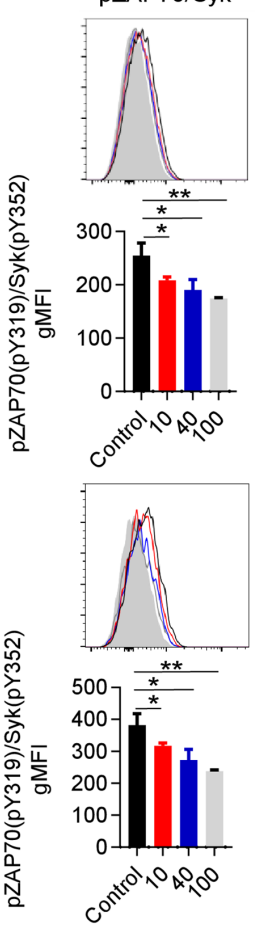

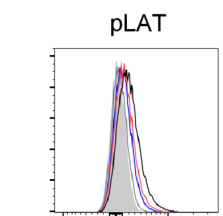
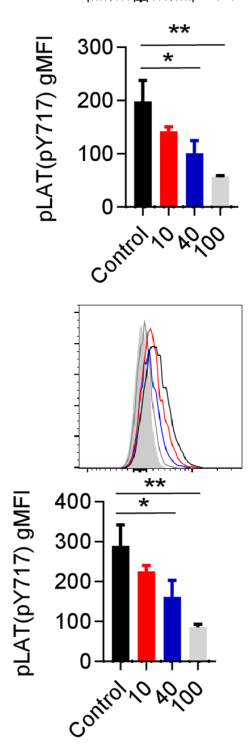
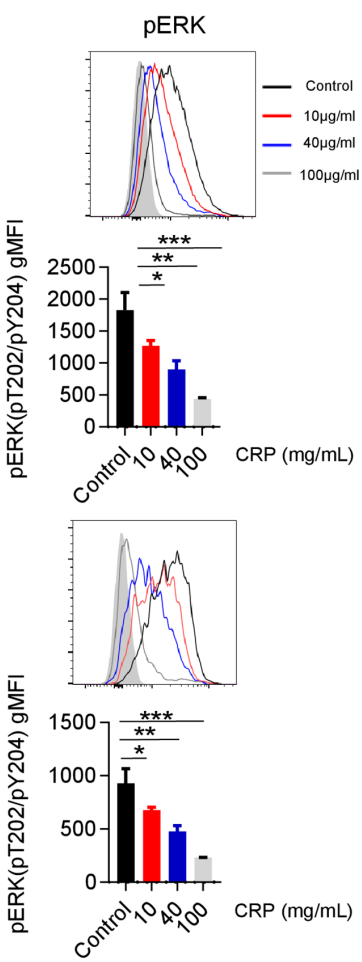

B.

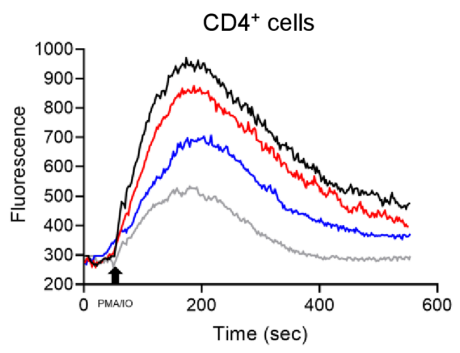

C.
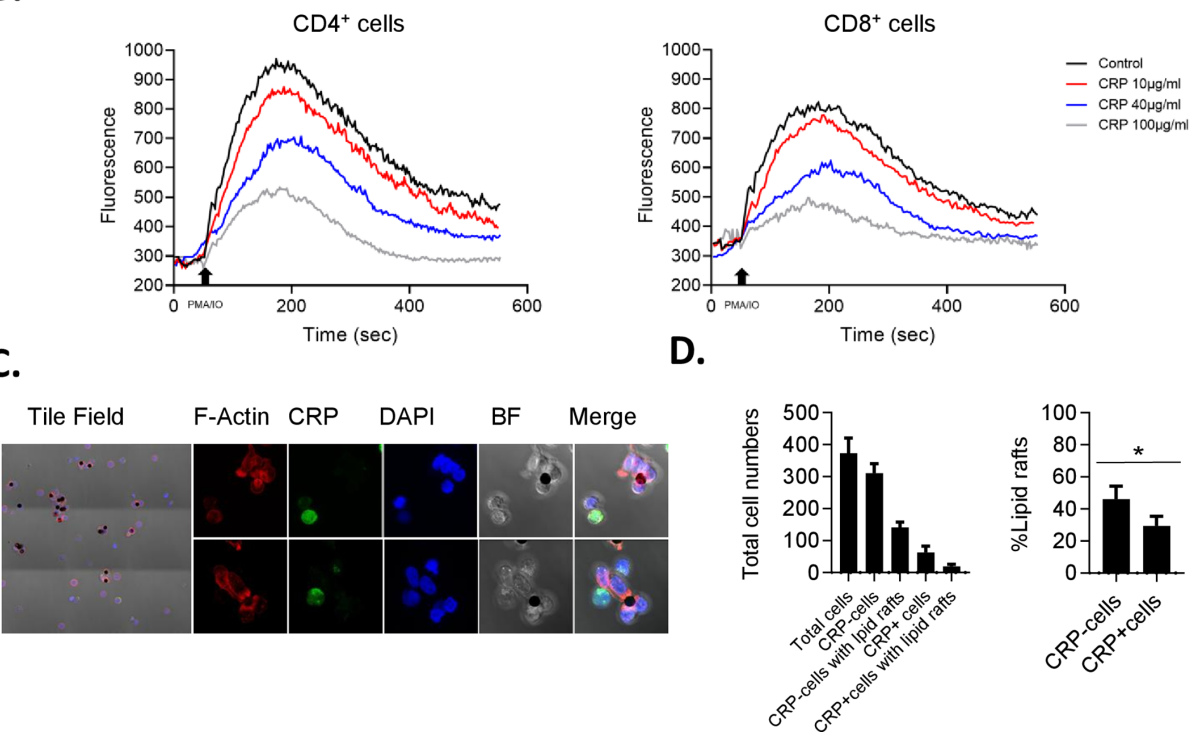

Figure $3 \mathrm{C}$ reactive protein (CRP) inhibits T-cell receptor (TCR) signaling pathway in T cells. (A) Expression of phosphorylated LCK (pY505), ZAP70(pY319)/Syk(pY352), LAT(pY717), ERK(pT202/pY204) and AKT(pS473) on CD3+ T cells pretreated with CRP at 10,40 and $100 \mu \mathrm{g} / \mathrm{mL}$ for 72 hours and concomitantly stimulated with $\mathrm{H}_{2} \mathrm{O}_{2}$ are from one representative of five similar patients. ${ }^{\star} \mathrm{P}<0.05,{ }^{* \star} \mathrm{p}<0.01,{ }^{\star \star \star} \mathrm{p}<0.001$ relative to cells with no treatment. (B) Representative data from three patients of calcium influx on T cells. CD3+ Tcells treated with CRP for 24 hours at $10-100 \mu \mathrm{g} / \mathrm{mL}$ were activated with phorbol 12-myristate 13-acetate (PMA) and ionomycin. (C and D) Anti-CD3/CD28 monoclonal antibodies (mAbs) Dynabeads recruit lipid rafts of CD3+ cells to form immunological synapses. CRP $(40 \mu \mathrm{g} / \mathrm{mL})$ treated CD3+ T cells stained with anti-CRP antibody (green) were significantly less likely to recruit lipid rafts to form the immunological synapse at the bead-T cell interface denoted by Phallodin staining (red) that control treated CD3+ T cells. Representative tiled image and high-magnification images from one of three patients.

CD83. Purified CD14+ monocytes were cultured with GM-CSF and IL-4 for 5 days, then iDCs were treated with CRP for 72 hours, and stimulated with LPS in order to induce maturation. CRP inhibited CD83 expression after LPS-induced maturation $(\mathrm{p}=0.05)$, although CRP did not change CD83 expression on imDCs (figure 4A,B).
We next examined whether CRP affected expression of costimulatory markers (CD40, CD80 and CD86), MHC) (HLA-ABC, HLA-DR and $\beta 2$-microgulobulin) and checkpoint ligands (PD-L1) on iDCs and mDCs pretreated with CRP before maturation (figure $4 \mathrm{~A}, \mathrm{~B}$ ). $\mathrm{mDCs}$ pretreated with $40 \mu \mathrm{g} / \mathrm{mL}$ CRP exhibited a reduction of CD40 ( $\mathrm{p}=0.003)$, 
A.

mDCs
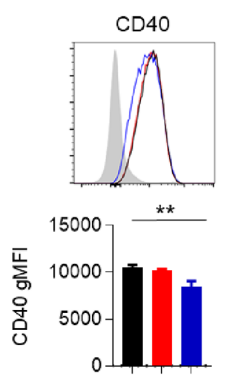

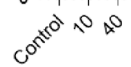

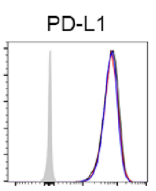

80000

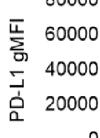

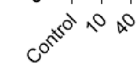

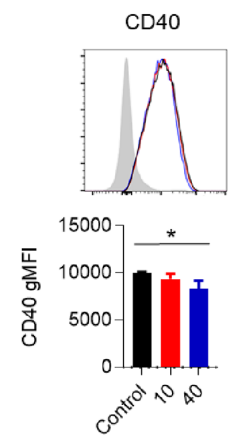

B.

imDCs
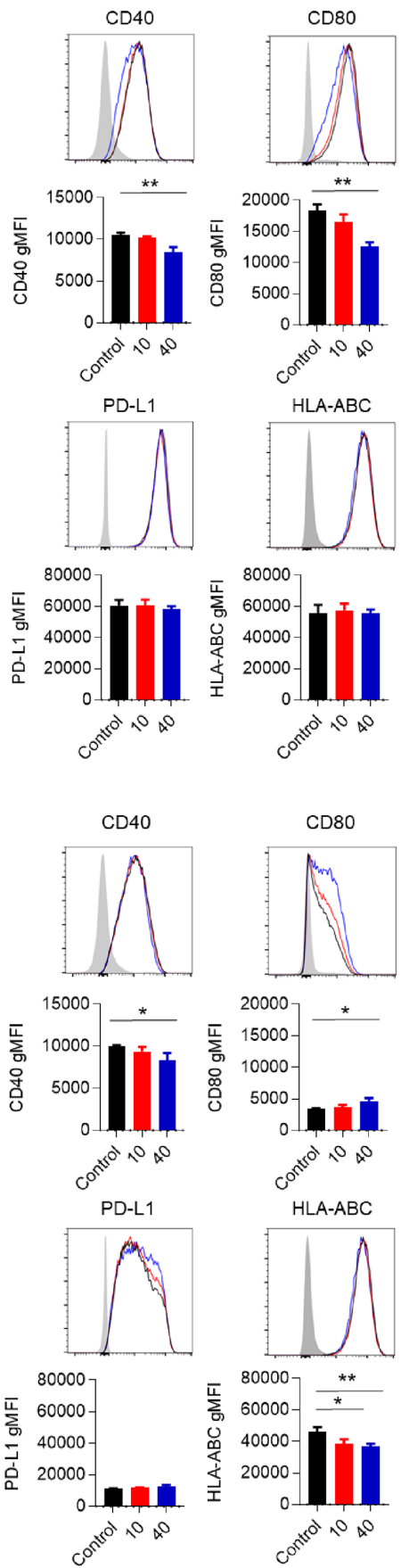

HLA-ABC
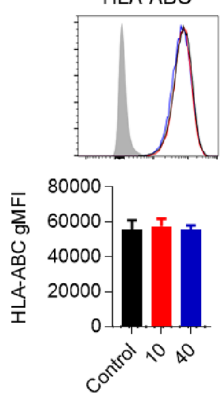
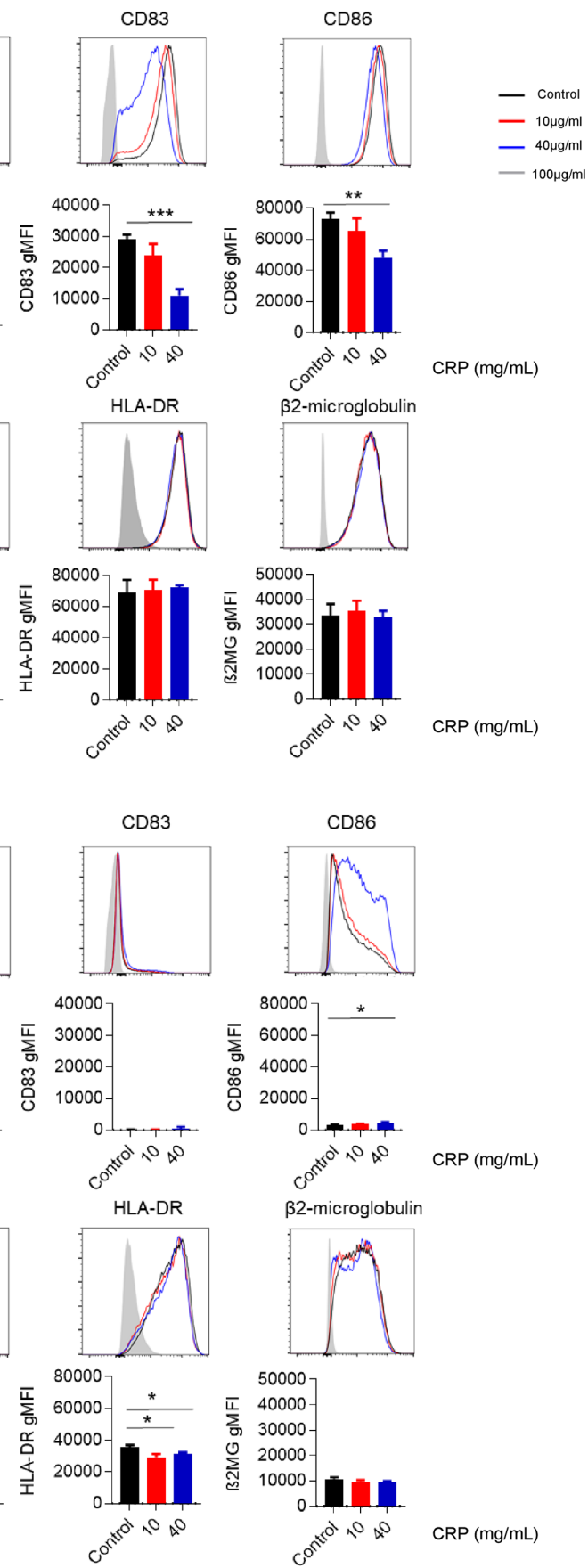

Figure $4 \mathrm{C}$ reactive protein (CRP) inhibits function, costimulatory and checkpoint proteins on dendritic cells (DCs). Frequency of mature (A) and immature (B) DCs treated with CRP at 10 and $40 \mu \mathrm{g} / \mathrm{mL}$ for 48 hours expressed costimulatory markers (CD40, CD80, CD83, CD86, PD-L1, HLA-ABC, HLA-DR and beta-2 microglobulin). Representative data are from one of five patients. Error bars are + SEM for triplicate samples assessed. ${ }^{* \star} \mathrm{P}<0.05,{ }^{* \star} \mathrm{p}<0.01,{ }^{* \star} \mathrm{p}<0.001$ relative to cells with no treatment.

CD80 ( $\mathrm{p}=0.001)$ and $\operatorname{CD} 86(\mathrm{p}=0.002)$ relative to control mDCs. Oppositely, $40 \mu \mathrm{g} / \mathrm{mL}$ CRP increased CD80 ( $\mathrm{p}=0.015)$ and CD86 ( $\mathrm{p}=0.015)$ expression on iDCs. CRP did not change PD-L1, HLA-ABC, HLA-DR or $\beta 2-$ microglobulin expression by mDCs, but decreased CD40 ( $\mathrm{p}=0.034)$, HLA-ABC $(\mathrm{p}=0.005)$ and HLA-DR $(\mathrm{p}=0.0203)$ expression on imDCs.

CRP inhibits expansion of antigen-specific $T$ cells

Given the inhibitory effects observed on T-cell function and DCs phenotypes by CRP, we evaluated whether CRP inhibited generation of antigen-specific CD8+ Tcells from patients with melanoma. Melan-A-specific CD8+ Tcells were expanded ex vivo for 7 days with peptidepulsed PBMC acting as autologous APCs in HLA A*0201 patient samples, increasing from undetectable levels to approximately $0.5 \%-1 \%$ of total CD8+ T cells. However, CRP exposure in vitro suppressed expansion of Melan-A tetramer-positive (Tet+) CD8+ T cells in a dose-dependent manner (figure 5A). In addition, Ki67 expression 
A.
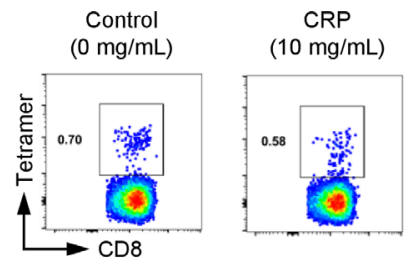

CRP

(40 mg/mL)

B.
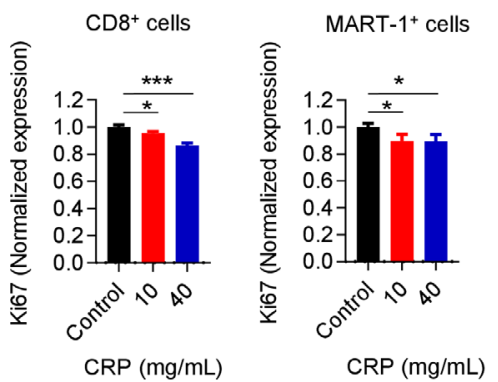

C.

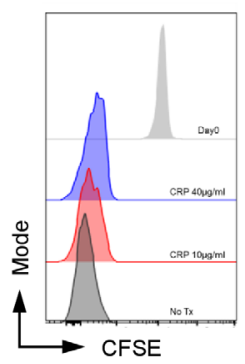

E.

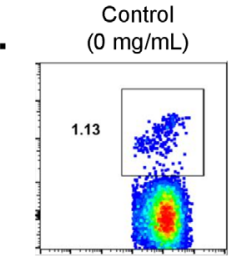

CRP $(40 \mathrm{mg} / \mathrm{mL})$ for CD8 ${ }^{+}$-cells

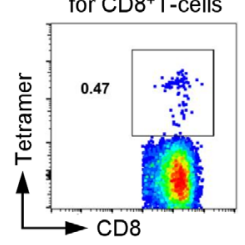

MART-1+ cells

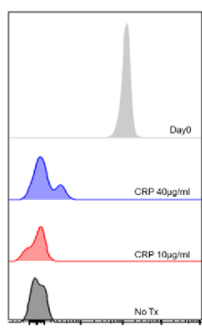

CRP $(40 \mathrm{mg} / \mathrm{mL})$

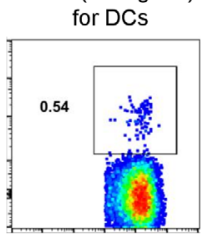

CRP $(40 \mathrm{mg} / \mathrm{mL})$ fo CD8 ${ }^{+} \mathrm{T}$-cells and DCs

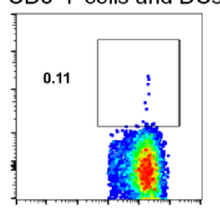

G.

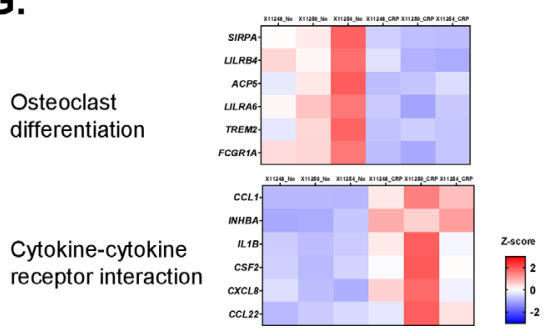

Figure 5 C reactive protein (CRP) inhibits the expansion of antigen-specific T cells. (A) MART-1-specific CD8 T-cell expansion. CD8+ Tcells isolated from HLA-A*0201 patients with melanoma were stimulated by $\gamma$-irradiated, MART- ${ }_{26-35}$ peptide-pulsed peripheral blood mononuclear cells (PBMCs) (antigen-presenting cells (APCs)) for 7 days in presence of different CRP concentration $(0,10,40 \mu \mathrm{g} / \mathrm{mL})$. (B and C) Ki67 expression and proliferation by CFSE-labeled Melan-A-specific CD8+ Tcells and MART-1 tetramer-positive T cells stimulated by $\gamma$-irradiated MART- $1_{26-35}$ peptide pulsed APC. (D) Scheme for assessing whether CRP-impaired generation of Melan-A-positive CD8+ Tcells was due to its effect on T cells and/or on mature dendritic cells (mDCs). (E) Purified CD8+ Tcells and mDCs separately before co-culture were treated with CRP for 48 hours, and co-cultured with MART-1 peptide-pulsed mDCs. Results shown are representative of three patients assessed over three independent experiments. (F) Volcano plot for the differential expression of total genes. The $y$-axis corresponds to negative log10 transformed adjusted $p$ value, and the $x$-axis displays the log2 fold change gene expression value. The red and blue dots represent the significantly differential expressed transcripts (adjusted $p$ value $<0.05$ ); the gray dots represent the transcripts whose expression levels did not reach statistical significance (adjusted $p$ value $>0.05$ ). (G) Expression heat map of genes associated with cytokine-cytokine receptor interaction pathway, and osteoclast differentiation pathway. Error bars are +SEM for triplicate samples assessed. ${ }^{\star \star} \mathrm{P}<0.05,{ }^{\star \star} \mathrm{p}<0.01,{ }^{* \star \star} \mathrm{p}<0.001$ relative to cells with no CRP treatment.

$(\mathrm{p}<0.05)$ and proliferation by CFSE-labeled CD8+ Tcells and Melan-A-specific CD8+ Tcells were decreased after CRP treatment at either 10 or $40 \mu \mathrm{g} / \mathrm{mL}$ (figure 5B-C).

\section{CRP affects DCs and CD8+ T cells in inhibiting expansion of MART-1-specific T cells}

To determine whether the impaired generation of MelanA-specific CD8+ T cells after CRP treatment was primarily 
due to its effect on T cells and/or on DCs, CRP was added to purified cultures of CD8+ T cells and mDCs separately for 48 hours before co-culture (figure 5D). Exposure to CRP decreased the number of Melan-A-specific CD8+ T cells whether $\mathrm{T}$ cells or mDCs were treated with CRP, and the greatest reduction came with concomitant treatment of T cells and DCs (figure 5E).

\section{CRP upregulates IL-1 $\beta$ in expanded MART-1specific T cells}

To gain further insight into the direct impact of CRP on T cells, paired samples of CD8+ Tcells activated with HLA-A *0201-restricted Melan-A peptide 26-35 ${ }_{(27 \mathrm{~L})}$ pulsed PBMCs, in the presence of absence of CRP $(40 \mu \mathrm{g} / \mathrm{mL})$ were assessed by RNA-Seq for three patients. Changes in gene expression of $\mathrm{T}$ cells treated with CRP compared with no CRP treatment were assessed for each patient (figure 5F). CRP consistently upregulated the expression of the $I L-1 \beta$ gene, a known stimulator of the production of CRP by hepatocytes $(\log 2 \mathrm{FC}=3.4$, and adjusted $\mathrm{p}$ value (q value $)=0.00015)$, in CD8+ T cells. Additionally, we evaluated IL-1 $\beta$ levels in culture supernatants from $\mathrm{T}$ cells treated with CRP, and found that CRP increased IL-1 $\beta$ levels in a dose-dependent manner (online supplementary figure 7). Next, pathways associated with significant peaks of RNA expression were evaluated using Enrichr referenced to the KEGG 2016 pathways database (online supplementary table 2) ${ }^{2627}$ The most significantly upregulated pathway in CRP-treated CD8+ T cells was cytokinecytokine receptor interaction pathway including $I L-1 \beta$, $C C L 1$ and CCL22 (figure 5G, adjusted $\mathrm{p}$ value ( $\mathrm{q}$ value) $<0.0001)$. The top six upregulated pathways included $I L-1 \beta$ and three of them included complement components. The pathway most downregulated by CRP were the osteoclast differentiation pathway (figure $5 \mathrm{G}$ q value $<0.0001$ ), and all six of the top downregulated pathways included elements involved with antigen presentation.

\section{Serum CRP levels are associated with clinical efficacy of PD-1 and CTLA-4 blockade}

We measured serum CRP in patients with advanced melanoma from the Checkmate-064 trial ${ }^{15}$ by a Luminex assay to determine if baseline CRP levels were associated with response to nivolumab (anti-PD-1) and ipilimumab (antiCTLA-4). In the trial, 140 patients were enrolled and randomly assigned to nivolumab for 12 weeks followed by ipilimumab for 12 weeks or to the reverse sequence of ipilimumab followed by nivolumab, of whom 68 and 70 patients, respectively, received at least one dose of study drug. Among these patients, 95 serum samples obtained before study drug administration were available for the analysis (figure 6A). Patient demographics are reported in online supplementary table 1 . As seen in figure 6B, overall survival was significantly worse in patients with baseline CRP levels higher than the median $(15.48 \mu \mathrm{g} / \mathrm{mL})$ compared with those with levels lower than the median initially receiving nivolumab or ipilimumab $(\mathrm{p}=0.001$ and 0.0002 , respectively).

\section{DISCUSSION}

Acute phase proteins (APP) synthesized in the liver, particularly CRP, have been associated with a variety of detrimental chronic inflammatory states, including infection, diabetes and ischemic heart disease. ${ }^{28}$ The short pentraxins like CRP or serum amyloid A are secreted pattern recognition receptors and play a role in antibacterial defense as opsonins by binding to apoptotic cell membrane components including phosphatidylcholine and phosphatidylethanolamine. ${ }^{29}$ Pro-inflammatory cytokines such as IL-1 $\beta$, IL- 8 , TNF- $\alpha$ or IL-6 induce hepatic and monocyte-derived production of a number of APPs, including CRP, via transcriptional activation of the STAT3, C/EBP and NF-KB pathways. ${ }^{30}$ Levels of CRP have long been observed to be elevated in patients with a variety of advanced cancers with levels as high as $500 \mu \mathrm{g} / \mathrm{mL}$, yet a role of CRP and other APPs in modulating the antitumor immune response has not been previously explored in detail. In the current work, we show that CRP has a profound suppressive effect on adaptive immunity in patients with melanoma. Up to $40 \%$ of CD 8 T cells bound and internalized CRP, and high levels of CRP diminished the proliferation of CD4+ and CD8+ T cells from patients with melanoma, and it downregulated DC function and altered T-cell and DC phenotypes, which is consistent with previous reports on APCs. ${ }^{11}{ }^{31}$ In T cells, CRP was rapidly internalized in a significant proportion of $\mathrm{T}$ cells and inhibited the immune synapse, leading to suppression of the earliest events in TCR engagement, including calcium flux and TCR signaling, resulting in a chronic state of immune suppression which has been shown to be associated with a poor outcome with the use of PD-1 blockade in melanoma and lung cancer. Additionally, RNA-seq analysis suggested that CRP upregulated expression of $I L-1 \beta$ gene, a known stimulator of CRP by hepatocytes. CRP also upregulated CCL1 and CCL22 genes, which can attract regulatory $\mathrm{T}$ cells to the tumor microenvironment, although CRP did not have any impact on the frequency of peripheral blood regulatory $\mathrm{T}$ cells (data not shown) ${ }^{32}$ In contrast, CRP inhibited the osteoclast differentiation pathway which is associated with antigen presentation to $\mathrm{CD} 8+$ T cells. ${ }^{33}$ The data presented herein suggest that CRP may be responsible for a state of systemic immune suppression in patients with cancer by impacting on both effector T cells and antigen presentation, consistent with previous reports that CRP is associated with a poor clinical outcome for diverse cancers and with checkpoint blockade therapies in melanoma and other malignancies. ${ }^{13} 14$ Our work evaluated the impact of CRP on peripheral blood T cells and DCs from patients with melanoma, and did not explore the effects of CRP on neoantigen-specific $\mathrm{T}$ cells or immunity within the tumor microenvironment. CRP was taken up by activated, proliferating $\mathrm{T}$ cells, by mechanisms that are as yet unclear. Further studies, including an assessment of the impact of APPs on antitumor immunity using tumor spheroids are planned as part of an ongoing clinical trial. The role of CRP on T-cell responses and resistance to PD-1 blockade 
A.

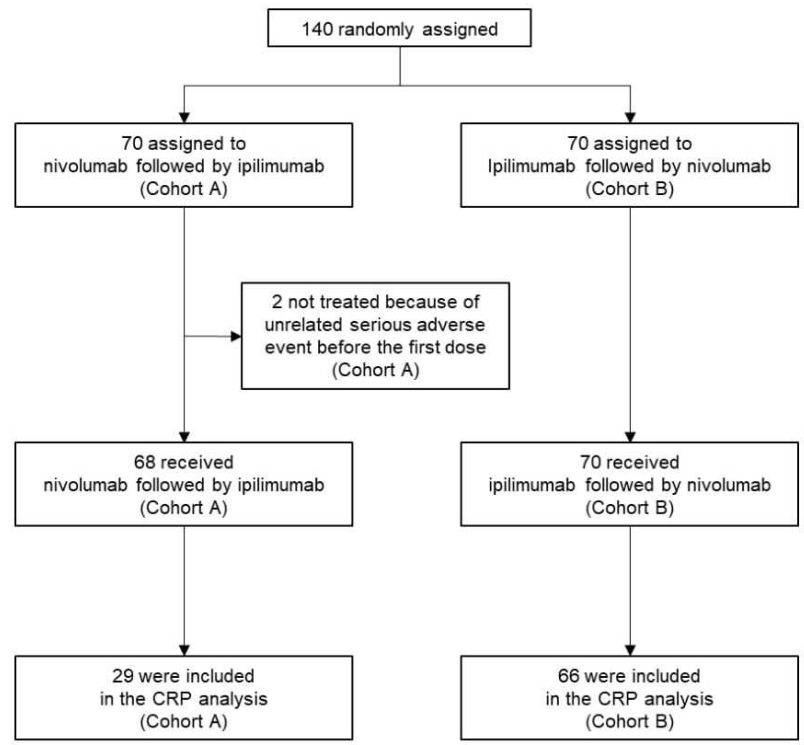

B.
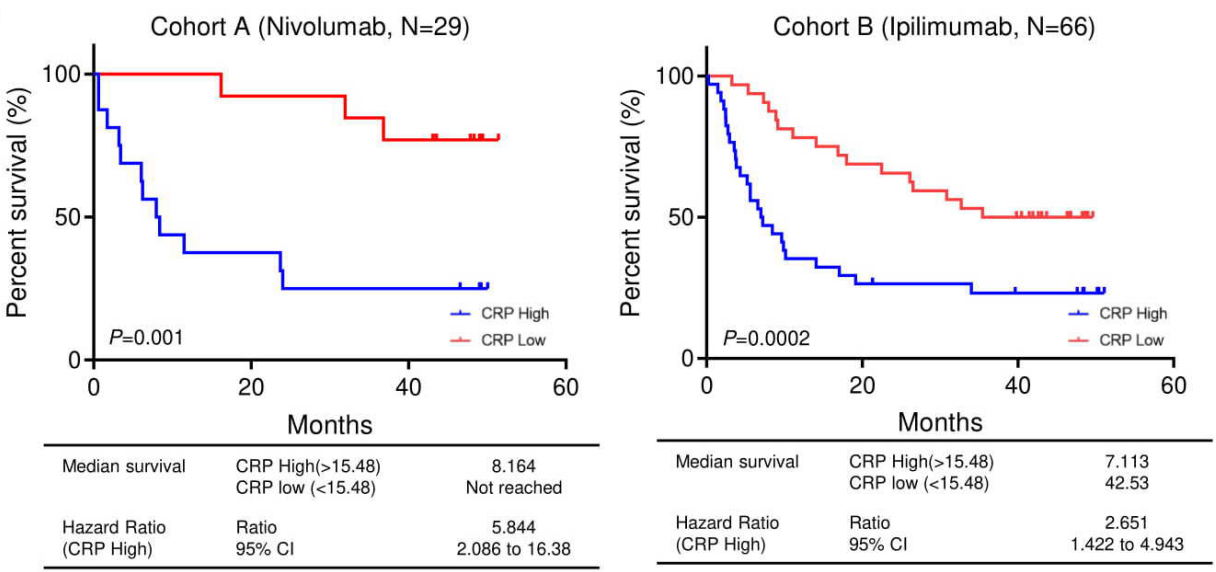

Figure 6 Serum $C$ reactive protein (CRP) levels in treatment-naïve patients receiving nivolumab (cohort A) or ipilimumab (cohort B) from the Checkmate-064 trial. (A) Consolidated Standards of Reporting Trials diagram for the study. Among 140 patients enrolled in the Checkmate-064 trial, 95 serum samples before administration of study drug were obtained for CRP analysis (29 from cohort A, 66 from cohort B). (B) Kaplan-Meier plot of the relation of overall survival (OS) to CRP levels before treatment. Cut-off point was at the median $(15.48 \mu \mathrm{g} / \mathrm{mL})$. The red curve represents survival for patients below the median, and the blue curve shows survival for those patients above the median. The survival probabilities were estimated using the KaplanMeier method, where differences in the variables were calculated using the log-rank test.

has also not been evaluated in murine models, and the differences in protein sequence and function of CRP in mice and humans may render such studies problematic. ${ }^{34}$

CRP has been shown in mice to facilitate the opsonization of bacteria by binding to Fc gamma receptors, yet in this work, blockade of Fc gamma receptors did not impact on the adaptive immunosuppression observed with CRP. ${ }^{35}$ The levels of CRP that were associated with suppression of T-cell and DC function $(10-40 \mu \mathrm{g} / \mathrm{mL})$ in this study are observed in the serum of many patients with advanced cancer. The finding in this study that serum CRP levels are associated with overall survival in patients with stage IV melanoma treated with nivolumab or ipilimumab further support an immune suppressive role for CRP and possibly other APPs and suggest a novel mechanism for resistance to PD-1 blockade in melanoma that may be applicable to other cancers. CRP has been shown to alter DC maturation and function in murine models, ${ }^{31}$ although it has not been previously shown to behave similarly with human DCs, and few investigations have explored the impact of high levels of CRP on human T cells.

There are considerable data supporting reduction of CRP as an anticancer strategy. CRP has been described as a prognostic factor for outcome in patients with melanoma, as has serum amyloid A. ${ }^{36} 37$ Antibodies against IL-1 $\beta$ and IL-6 receptor that block liver and monocyte synthesis of CRP and other APPs have been tested in patients and are Food and Drug Administration (FDA) approved for a variety of indications. Tocilizumab, a humanized anti-IL-6R $\alpha$ antibody that is FDA approved for the treatment of rheumatoid arthritis, juvenile idiopathic arthritis and polyarticular juvenile rheumatoid 
arthritis, has been shown in patients with cancer to suppress the cytokine release syndrome (CRS) observed with the use of chimeric antigen receptor (CAR)-T-cell therapy and is approved for that indication by the FDA, and more recently was demonstrated to reverse PD-1 blockade-associated immune-related adverse events. ${ }^{38} 39$ Blockade of IL-6R $\alpha$ resulted in a significant decrease in serum CRP that was associated with rapid resolution of immune-related adverse events in one report. ${ }^{40}$ When tocilizumab was used to treat CRS, onset of the condition and recovery was associated with changes in CRP levels, and had no impact on the therapeutic effect of the transferred CAR-T cells. ${ }^{3611}$ Tocilizumab was used in a patient with Crohn's disease and melanoma in combination with a PD-1 blocking antibody, and resulted in a sustained complete antitumor response without causing a flare of the colitis. ${ }^{42}$

The IL-1 $\beta$ blocking antibody canakinumab was used in a cardiac prevention trial to test the hypothesis that it could reduce the incidence of heart attack, stroke or cardiovascular death in patients with elevated CRP, a biomarker for cardiovascular risk. There was a significant reduction in incidence of lung cancer noted in that trial. ${ }^{43}$ Reduction in both cardiac events and lung cancer diagnoses was associated with extent of reduction of serum CRP levels. ${ }^{44}$ There are many different explanations for the reduction in incidence of lung cancer, but the adaptive immune suppressive role for CRP suggested by our data herein suggest that a re-invigorated immune response may at least in part be responsible. Our data would support the use of tocilizumab or canakinumab in combination with PD-1 blockade, and a trial of the former antibody is currently being pursued in patients with metastatic melanoma that are receiving PD-1 and CTLA-4 blockade (NCT03999749).

\section{CONCLUSIONS}

Elevated levels of acute phase proteins, particularly CRP, are associated with a poor outcome in cancer, but the mechanism by which that occurs is unclear. We found that CRP bound to T cells, suppressed signaling events early in TCR engagement and downregulated antigen-presenting function in melanoma.

Acknowledgements The authors would like to thank the colleagues from BristolMyers Squibb including Christine Horak and Megan Wind-Rotolo for their insight and assistance as well as for providing nivolumab. The authors would also like to thank the Genome Technology Center and Microscopy Laboratory at NYU Langone Health for their assistance.

Contributors TY: designed and conducted experiments; analyzed and interpreted results; assembled manuscript. Jl: designed and conducted experiments; analyzed and interpreted results; assembled manuscript. IG: designed and conducted experiments; analyzed and interpreted results. ASL: designed and conducted experiments; analyzed and interpreted results; assisted in assembly of manuscript. YH: analyzed the data on RNA-seq. MK: designed and conducted experiments; analyzed and interpreted results; assisted in assembly of manuscript. MV: designed and conducted experiments; analyzed and interpreted results; assisted in assembly of manuscript. DMW: designed and conducted experiments; analyzed and interpreted results.
Funding This work was supported by grant funding from the National Cancer Institute (grant number R01CA175732).

Competing interests JW: honoraria and travel from BMS, Merck, GSK, Genentech, AstraZeneca, Pfizer, CytoMx, EMD Serono, Incyte. Stock in Biond, Altor, Protean, CytoMx, Celldex, Sellas. Research funding from NextCure. All other clinical research funding to my institution, not me. Named on a patent for a PD-1 biomarker by Biodesix not used in this work. Named on a CTLA-4 biomarker patent by Moffitt Cancer Center not used in this work. Named on a patent for the use of 41-BB antibody for tumor infiltrating lymphocyte growth by Moffitt Cancer Center not used in this work.

\section{Patient consent for publication Not required.}

Provenance and peer review Not commissioned; externally peer reviewed.

Data availability statement Data are available on reasonable request.

Open access This is an open access article distributed in accordance with the Creative Commons Attribution Non Commercial (CC BY-NC 4.0) license, which permits others to distribute, remix, adapt, build upon this work non-commercially, and license their derivative works on different terms, provided the original work is properly cited, appropriate credit is given, any changes made indicated, and the use is non-commercial. See http://creativecommons.org/licenses/by-nc/4.0/.

\section{ORCID iD}

Tatsuya Yoshida http://orcid.org/0000-0003-4896-5824

\section{REFERENCES}

1 Du Clos TW. Function of C-reactive protein. Ann Med 2000;32:274-8.

2 Gabay C, Kushner I. Acute-Phase proteins and other systemic responses to inflammation. N Engl J Med 1999;340:448-54.

3 Yamashita H, Shimada K, Seki E, et al. Concentrations of interleukins, interferon, and C-reactive protein in stable and unstable angina pectoris. Am J Cardiol 2003;91:133-6.

4 Yang J, Liu Z, Liu H, et al. C-Reactive protein promotes bone destruction in human myeloma through the CD32-p38 MAPK-Twist axis. Sci Signal 2017;10. doi:10.1126/scisignal.aan6282. [Epub ahead of print: 12 Dec 2017].

5 Agnoli C, Grioni S, Pala V, et al. Biomarkers of inflammation and breast cancer risk: a case-control study nested in the EPIC-Varese cohort. Sci Rep 2017;7:12708.

6 Yasuda Y, Saito K, Yuasa T, et al. Early response of C-reactive protein as a predictor of survival in patients with metastatic renal cell carcinoma treated with tyrosine kinase inhibitors. Int J Clin Oncol 2017;22:1081-6.

7 Hang J, Xue P, Yang H, et al. Pretreatment C-reactive protein to albumin ratio for predicting overall survival in advanced pancreatic cancer patients. Sci Rep 2017;7:2993.

8 Pastorino U, Morelli D, Leuzzi G, et al. Baseline and postoperative Creactive protein levels predict mortality in operable lung cancer. Eur $J$ Cancer 2017;79:90-7.

9 Akamine T, Takada K, Toyokawa G, et al. Association of preoperative serum CRP with PD-L1 expression in 508 patients with non-small cell lung cancer: a comprehensive analysis of systemic inflammatory markers. Surg Oncol 2018;27:88-94.

10 Zhang L, Liu S-H, Wright TT, et al. C-Reactive protein directly suppresses Th1 cell differentiation and alleviates experimental autoimmune encephalomyelitis. J Immunol 2015;194:5243-52.

11 Zhang R, Becnel L, Li M, et al. C-Reactive protein impairs human CD14+ monocyte-derived dendritic cell differentiation, maturation and function. Eur J Immunol 2006;36:2993-3006.

12 Tarhini AA, Cherian J, Moschos SJ, et al. Safety and efficacy of combination immunotherapy with interferon alfa- $2 b$ and tremelimumab in patients with stage IV melanoma. $J$ Clin Oncol 2012;30:322-8.

13 Oya $\mathrm{Y}$, Yoshida T, Kuroda $\mathrm{H}$, et al. Predictive clinical parameters for the response of nivolumab in pretreated advanced non-small-cell lung cancer. Oncotarget 2017;8:103117-28.

14 Weber JS, Sznol M, Sullivan RJ, et al. A serum protein signature associated with outcome after anti-PD-1 therapy in metastatic melanoma. Cancer Immunol Res 2018;6:79-86.

15 Weber JS, Gibney G, Sullivan RJ, et al. Sequential administration of nivolumab and ipilimumab with a planned switch in patients with advanced melanoma (CheckMate 064): an open-label, randomised, phase 2 trial. Lancet Oncol 2016;17:943-55.

16 Maeda Y, Nishikawa H, Sugiyama D, et al. Detection of self-reactive $\mathrm{CD}^{+} \mathrm{T}$ cells with an anergic phenotype in healthy individuals. Science 2014;346:1536-40. 
17 Lin Y, Gallardo HF, Ku GY, et al. Optimization and validation of a robust human T-cell culture method for monitoring phenotypic and polyfunctional antigen-specific CD4 and CD8 T-cell responses. Cytotherapy 2009;11:912-22.

18 Dobin A, Davis CA, Schlesinger F, et al. Star: ultrafast universal RNAseq aligner. Bioinformatics 2013;29:15-21.

19 Liao Y, Smyth GK, Shi W. featureCounts: an efficient General purpose program for assigning sequence reads to genomic features. Bioinformatics 2014;30:923-30.

20 Love MI, Huber W, Anders S. Moderated estimation of fold change and dispersion for RNA-Seq data with DESeq2. Genome Biol 2014;15:550.

21 Viola A, Schroeder S, Sakakibara Y, et al. T Iymphocyte costimulation mediated by reorganization of membrane microdomains. Science 1999;283:680-2.

22 Nicolaou SA, Neumeier L, Peng Y, et al. The Ca(2+)-activated K(+) channel KCa3.1 compartmentalizes in the immunological synapse of human T lymphocytes. Am J Physiol Cell Physiol 2007;292:C1431-9.

$23 \mathrm{Lu}$ J, Marnell LL, Marjon KD, et al. Structural recognition and functional activation of FcgammaR by innate pentraxins. Nature 2008:456:989-92.

24 Griffith CE, Zhang W, Wange RL. ZAP-70-dependent and -independent activation of ERK in Jurkat T cells. Differences in signaling induced by $\mathrm{H} 2 \mathrm{O} 2$ and CD3 cross-linking. J Biol Chem 1998;273:10771-6.

25 Schieven GL, Mittler RS, Nadler SG, et al. Zap-70 tyrosine kinase, CD45, and T cell receptor involvement in UV- and H2O2-induced T cell signal transduction. J Biol Chem 1994;269:20718-26.

26 Chen EY, Tan CM, Kou Y, et al. Enrichr: interactive and collaborative HTML5 gene list enrichment analysis tool. BMC Bioinformatics 2013;14:128.

27 Kuleshov MV, Jones MR, Rouillard AD, et al. Enrichr: a comprehensive gene set enrichment analysis web server 2016 update. Nucleic Acids Res 2016;44:W90-7.

28 McFadyen JD, Kiefer J, Braig D, et al. Dissociation of C-reactive protein localizes and amplifies inflammation: evidence for a direct biological role of $\mathrm{C}$-reactive protein and its conformational changes. Front Immunol 2018;9:1351.

29 Litvack ML, Palaniyar N. Review: soluble innate immune patternrecognition proteins for clearing dying cells and cellular components: implications on exacerbating or resolving inflammation. Innate Immun 2010;16:191-200.

30 Agrawal A, Cha-Molstad H, Samols D, et al. Overexpressed nuclear factor-kappaB can participate in endogenous C-reactive protein induction, and enhances the effects of C/EBPbeta and signal transducer and activator of transcription-3. Immunology 2003:108:539-47.

31 Jimenez RV, Wright TT, Jones NR, et al. C-Reactive protein impairs dendritic cell development, maturation, and function: implications for peripheral tolerance. Front Immunol 2018;9:372

32 Kuehnemuth B, Piseddu I, Wiedemann GM, et al. Ccl1 is a major regulatory $T$ cell attracting factor in human breast cancer. $B M C$ Cancer 2018;18:1278.

33 D'Amico L, Roato I. Cross-Talk between T cells and osteoclasts in bone resorption. Bonekey Rep 2012;1:82.

34 Yunis I, Whitehead AS. The mouse C-reactive protein gene maps to distal chromosome 1 and, like its human counterpart, is closely linked to the serum amyloid P component gene. Immunogenetics 1990;32:361-3.

35 Thomas-Rudolph D, Du Clos TW, Snapper CM, et al. C-Reactive protein enhances immunity to Streptococcus pneumoniae by targeting uptake to Fc gamma R on dendritic cells. J Immunol 2007;178:7283-91

36 Fang S, Wang Y, Sui D, et al. C-Reactive protein as a marker of melanoma progression. J Clin Oncol 2015;33:1389-96.

37 Findeisen P, Zapatka M, Peccerella T, et al. Serum amyloid A as a prognostic marker in melanoma identified by proteomic profiling. $J$ Clin Oncol 2009;27:2199-208.

38 Brudno JN, Kochenderfer JN. Toxicities of chimeric antigen receptor T cells: recognition and management. Blood 2016;127:3321-30.

39 Teachey DT, Lacey SF, Shaw PA, et al. Identification of predictive biomarkers for cytokine release syndrome after chimeric antigen receptor T-cell therapy for acute lymphoblastic leukemia. Cancer Discov 2016:6:664-79.

40 Rossi J-F, Lu Z-Y, Jourdan M, et al. Interleukin-6 as a therapeutic target. Clin Cancer Res 2015;21:1248-57.

41 Norelli M, Camisa B, Barbiera G, et al. Monocyte-Derived IL-1 and IL-6 are differentially required for cytokine-release syndrome and neurotoxicity due to CAR T cells. Nat Med 2018;24:739-48.

42 Uemura M, Trinh VA, Haymaker C, et al. Selective inhibition of autoimmune exacerbation while preserving the anti-tumor clinical benefit using IL-6 blockade in a patient with advanced melanoma and Crohn's disease: a case report. J Hematol Oncol 2016;9:81.

43 Ridker PM, Everett BM, Thuren T, et al. Antiinflammatory therapy with canakinumab for atherosclerotic disease. $N$ Engl J Med 2017;377:1119-31.

44 Ridker PM, MacFadyen JG, Thuren T, et al. Effect of interleukin-1 $\beta$ inhibition with canakinumab on incident lung cancer in patients with atherosclerosis: exploratory results from a randomised, double-blind, placebo-controlled trial. Lancet 2017;390:1833-42. 


\section{Correction: $C$ reactive protein impairs adaptive immunity in immune cells of patients with melanoma}

Yoshida T, Ichikawa J, Giuroiu I, et al. C reactive protein impairs adaptive immunity in immune cells of patients with melanoma. J Immunother Cancer 2020;8:e00234. doi: 10.1136/jitc-2019-000234

In this article, the scale bars for Figure $2 \mathrm{~A}$ and $\mathrm{B}$ were missing their colour. The correct Figure 2 is below:

A.

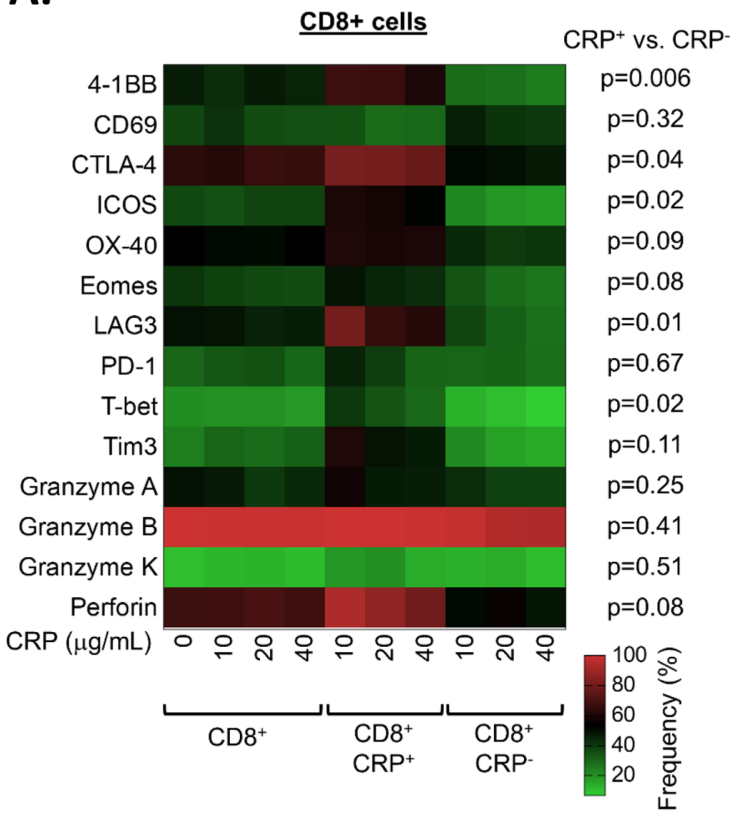

B.

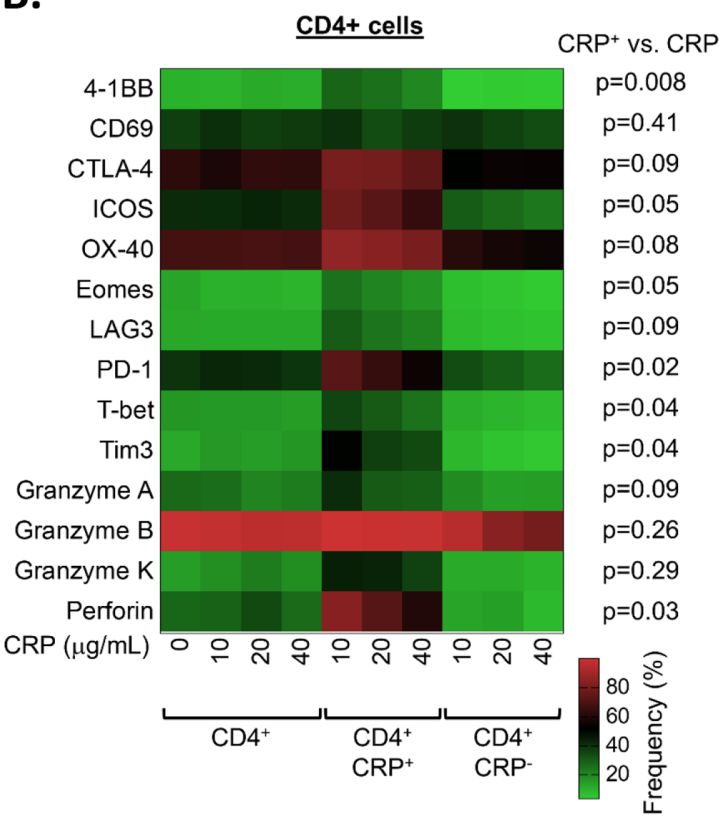

C.

$\mathrm{CD}^{+}$cells
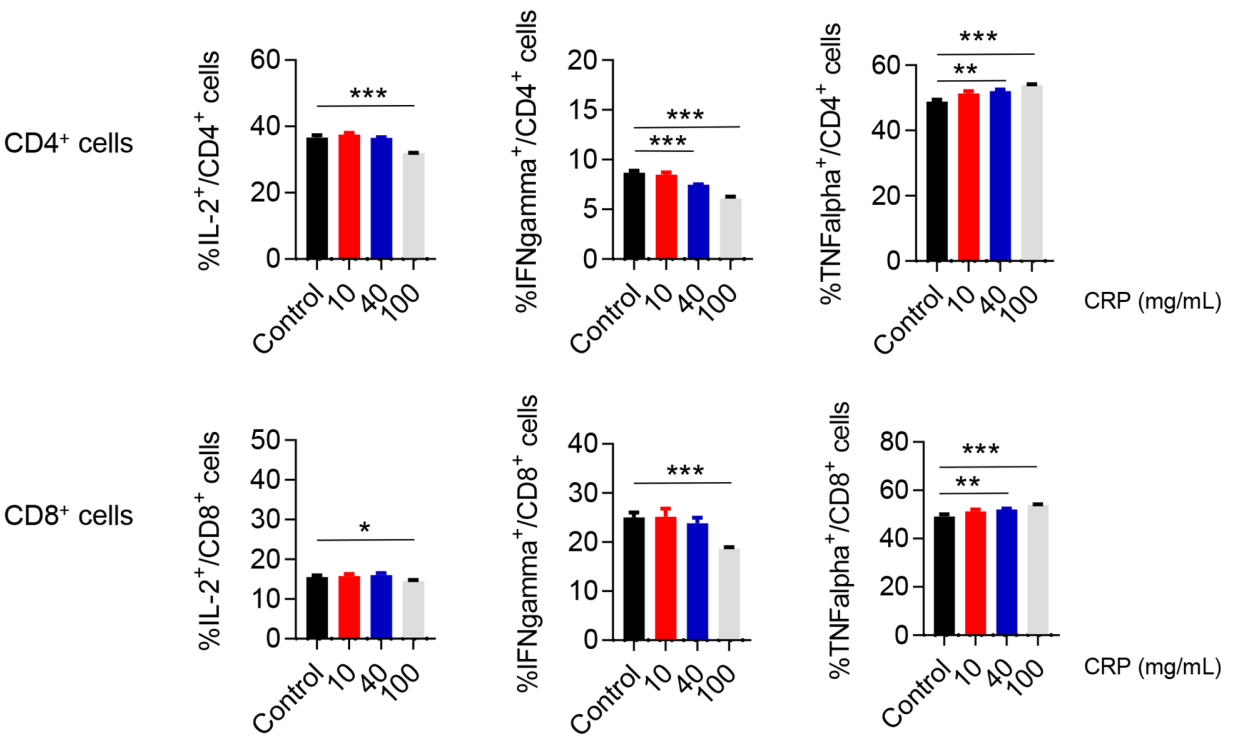

Open access This is an open access article distributed in accordance with the Creative Commons Attribution Non Commercial (CC BY-NC 4.0) license, which permits others to distribute, remix, adapt, build upon this work non-commercially, and license their derivative works on different terms, provided the original work is properly cited, appropriate credit is given, any changes made indicated, and the use is non-commercial. See: http://creativecommons.org/licenses/by-nc/4.0/. 
(C) Author(s) (or their employer(s)) 2020. Re-use permitted under CC BY-NC. No commercial re-use. See rights and permissions. Published by BMJ.

J Immunother Cancer 2020;8:e000234corr1. doi:10.1136/jitc-2019-000234corr1

(D) Check for updates 